\title{
Dangerous dive cycles and the proverbial ostrich
}

\author{
Alejandro Frid, Michael R. Heithaus and Lawrence M. Dill
}

A. Frid (alejandro_frid@alumni.sfu.ca) and L. M. Dill, Dept of Biological Sciences, Simon Fraser Univ., Burnaby, BC, Canada, V5A 1S6. Present address for AF: 352 Creek Road, RR1 I27, Bowen Island, BC, Canada, VON 1G0. - M. R. Heithaus, Dept of Biological Sciences, Marine Biology Program, Florida International Univ., Biscayne Bay Campus AC1, North Miami, FL 33181, USA.

\begin{abstract}
Data rarely are available to address the level of predation risk faced by diving animals in different parts of the water column. Consequently, most published research on diving behaviour implicitly assumes - like the proverbial ostrich - that 'unseen' predators are functionally unimportant. We argue that failure to consider diving in a predation risk framework may have precluded many insights into the ecology of aquatic foragers that breathe air. Using existing literature and a simple model, we suggest that fear from submerged predators in several systems might be influencing patch residence time, and therefore the duration of other dive cycle components. These analyses, along with an earlier model of predation risk faced by diving animals at the surface, suggest that dive cycle organisation can be modified to increase safety from predators, but only at the cost of reduced energy gain. Theoretical arguments presented here can seed hypotheses on factors contributing to population declines of diving species. For instance, adjustments to the dive cycle that reduce predation risk might be unaffordable if resources are scarce. Thus, if animals are to avoid imminent starvation or substantial loss of reproductive potential, resource declines might indirectly increase predation rates by limiting the extent to which dive cycles can deviate from those that would maximize energy gain. We hope that ideas presented in this paper stimulate other researchers to further develop theory and test predictions on how predation risk might influence diving behaviour and its ecological consequences.
\end{abstract}

Aquatic foragers that breathe air face unusual optimality problems (Kramer 1988). The time that they spend uploading oxygen at the surface affects the depth and time available to forage during the subsequent dive, yet is mutually exclusive with foraging itself. Deeper patches of prey may be richer, yet longer descents and ascents consume more oxygen and leave less aerobic dive time for exploiting the patch. Do long stays at shallow strata yield higher energetic returns than short forays at deeper and richer patches? Would more prey be captured with shorter surfacings and a greater number of shorter dives? When are the immediate benefits of a long anaerobic dive worth the ensuing lactate accumulation and extended recovery period? The literature on diving behaviour is rich with models asking these sort of questions (Ydenberg and Clark 1989, Houston and Carbone 1992, Carbone and Houston 1996, Mori 1998a, Thompson and Fedak 2001), and with empirical studies that test theoretical predictions (Wilson and Wilson 1988, Boyd et al.
1995, Mori et al. 2002, Mori and Boyd 2004, Wilson and Quintana 2004). With rare exceptions, however, this body of work considers only energetic currencies.

Fear of predators (sensu Brown et al. 1999) has been notoriously absent from the research agenda. This lacuna should seem surprising. Preceding and concurrent with the development of optimal diving theory, work on other systems has overwhelmingly revealed that behavioural decisions, more often than not, optimise trade-offs between resource gain and predator avoidance (Lima and Dill 1990, Lima 1998, Brown and Kotler 2004). Why should diving behaviour be any different?

Granted, it is difficult to quantify predator-prey behavioural interactions experienced by diving animals, particularly if these occur in submerged, deep, dark, and offshore environments. For instance, remains likely belonging to Antarctic fur seals (Arctocephalus gazella) have been found in the stomachs of sleeper sharks (Somniosus microcephalus) caught at $600 \mathrm{~m}$ depths (Cherel and Duhamel 2004), far deeper than the diving 
range of Antarctic fur seals. Was the seal flesh scavenged from sinking carcasses? Or do Antarctic sleeper sharks use the entire water column and overlap spatially with seals, as Greenland sharks ( $S$. microcephalus) in the northern hemisphere do (Skomal and Benz 2004)? But even if there is a spatial overlap, do Somniosus or other deep-water sharks actually hunt pinnipeds? Data rarely are available to address these sorts of questions.

Researchers of diving behaviour have responded to such data gaps by implicitly assuming, like the proverbial ostrich, that unseen predators are functionally unimportant. This de facto ousting of a predation risk framework from the study of diving behaviour may have precluded many insights into the ecology of aquatic foragers that breathe air (Heithaus and Frid 2003). Exceptions, of course, do exist. These include analyses suggesting that northern elephant seals (Mirounga angustirostris) migrating over the continental shelf engage in dive patterns that reduce their time at the surface, where silhouetting makes them highly visible from below and particularly vulnerable to white sharks (Carcharodon carcharia) (Le Boeuf and Crocker 1996). Similarly, other research suggests that migrating green turtles (Chelonia mydas) rest during the deeper portion of their dives to reduce risk from shark attacks at the surface (Hays et al. 2001). While these two studies begin to show a relationship between dive cycle organisation and predation risk, neither address how the dive-cycle organisation of animals engaged in foraging bouts responds to risk-energy tradeoffs.

Towards that goal, a recent study combining theory and empirical data suggests that harbour seals (Phoca vitulina richardsi) in Prince William Sound, Alaska, under-utilise resources found at depths where risk from Pacific sleeper sharks (S. pacificus) appears to be high (Frid et al., in press). Relative to the time allocation pattern that would maximise net energy gain, some individual seals appeared to have reduced the time spent per dive at dangerous foraging patches - the analog of higher giving-up-densities in terrestrial systems (Brown and Kotler 2004) - and also performed fewer dives to those patches. In addition to supporting the theoretical plausibility that predators influence diving decisions, that study suggested substantial variability in the willingness of individuals to take greater risks in order to increase energy gain (Frid et al., in press), possibly resulting from differences in body condition and residual reproductive value. Individual differences in risk-taking are consistent with life-history theory and field studies suggesting that individuals in poor body condition are more willing to take greater risks to avoid starvation or other imminent loss of reproductive potential (McNamara and Houston 1987, Sinclair and Arcese 1995). Applying this framework, our earlier work predicts mathematically that individuals in poor body condition should chose a dive cycle organisation that is energetically more profitable but more dangerous (i.e. longer patch residence times, in spite of higher encounter probabilities with deep-water predators) than individuals in good body condition (Frid et al. 2006). Here we explore further the possible influence of fear on diving behaviour by synthesising existing literature and contrasting predictions from energy-maximizing (EM) and fear-energy optimising (FEO) currencies.

An important prediction from EM currencies, later explained in more detail, is that residence time at patches of prey increases with depth, unless aerobic dives are very deep (Wilson and Wilson 1988, Houston and Carbone 1992, Carbone and Houston 1996, Mori 1998a, Thompson and Fedak 2001). The empirical literature, however, provides mixed support for this prediction (Table 1). These discrepancies intrigued us, and we use them as examples of how a FEO perspective might enhance understanding of diving behaviour.

Our arguments are most relevant to 'divers' rather than 'surfacers' (sensu Boyd 1997), but apply to surfacers during their foraging bouts. Divers spend most of their time at the surface or in non-aquatic habitats, but conduct short underwater forays which generally focus on foraging. Seabirds and most pinnipeds are among them, and these are the focal taxa for developing most of our arguments. In contrast, surfacers - which include northern elephant seals during atsea foraging trips, cetaceans, sea turtles, and sea snakes - are submerged most of the time and generally surface only for short periods of oxygen recovery. While underwater, surfacers not only feed, but also engage in long bouts of rest, travel and other activities (Rubinoff et al. 1986, Boyd 1997, Crocker et al. 1997, Hays et al. 2001), and the unique optimality problems associated with these behaviours are beyond our present scope.

\section{Dive cycle components}

A dive cycle, stripped to its essentials, consists of time spent at the surface acquiring oxygen, descent to a depth where resources are selected, foraging within the resource patch and ascent to the surface where the cycle renews. The duration of each phase is a set of correlated choices. Deeper dives are longer than shallow ones because they require more travel and often have longer residence times at resource patches, thereby requiring longer surfacings for oxygen acquisition (Kramer 1988, Houston and Carbone 1992).

Foraging depth arguably is the driving decision around which other dive cycle components adjust, at least when resource abundance and associated tradeoffs covary with depth. This premise is consistent with Wilson's (2003) penguin study, which demonstrated that surface intervals have a recovery phase that pays the 
Table 1. Literature examples for assessing the prediction from energy-maximizing models that patch residence time increases with depth unless aerobic dives are very deep (see text).

\begin{tabular}{|c|c|c|c|}
\hline Study & Species & Data type & $\begin{array}{l}\text { Prediction } \\
\text { supported? }\end{array}$ \\
\hline Beck et al. 2000 & Grey seal & $\begin{array}{l}\text { Mean durations of dive cycle and depths of } \\
\text { individuals (male and females pooled). These data } \\
\text { are a subset of Beck et al. (2003) }\end{array}$ & No \\
\hline Beck et al. 2003 & Grey seal & $\begin{array}{l}\text { Mean durations of dive cycle and depths for } \\
\text { shallow diving females and deeper diving males }\end{array}$ & No \\
\hline Boyd et al. 1995 & Antarctic fur seal & $\begin{array}{l}\text { Mean durations of dive cycle and median depths of } \\
\text { individual adult females }\end{array}$ & Yes \\
\hline Chappell et al. 1993 & Adélie penguin & $\begin{array}{l}\text { Mean values for } 455 \text { diving bouts pooled for } \\
\text { all individuals }\end{array}$ & No \\
\hline Costa and Gales 2000 & $\begin{array}{l}\text { New Zealand sea lion } \\
\text { (1997) }\end{array}$ & $\begin{array}{l}\text { Mean durations of dive cycle and depths of } \\
\text { individual adult females }\end{array}$ & No \\
\hline Costa and Gales 2003 & Australian sea lion & $\begin{array}{l}\text { Mean durations of dive cycle and depths of } \\
\text { individual adult females }\end{array}$ & No \\
\hline${ }^{*}$ Crocker et al. 2001 & $\begin{array}{l}\text { New Zealand sea lion } \\
\text { (1996) }\end{array}$ & $\begin{array}{l}\text { Mean durations of dive cycle and depths of } \\
\text { individual adult females }\end{array}$ & No \\
\hline Croll et al. 1992 & Thick-billed murre & $\begin{array}{l}\text { Patch residence time of individuals averaged } \\
\text { for depth bins }\end{array}$ & Yes \\
\hline Frid et al., in press & Harbour seal & $\begin{array}{l}\text { Mean durations of dive cycle and depths } \\
\text { of individuals }\end{array}$ & No \\
\hline Kooyman and Kooyman 1995 & Emperor penguin & $\begin{array}{l}\text { Patch residence time of individuals averaged } \\
\text { for depth bins }\end{array}$ & Yes \\
\hline Mattlin et al. 1998 & New Zealand fur seal & $\begin{array}{l}\text { Mean durations of dive cycle and depths of } \\
\text { individual females }\end{array}$ & Yes \\
\hline Wilson and Wilson 1988 & $\begin{array}{l}\text { Crowned and cape } \\
\text { cormorants }\end{array}$ & Individual dive cycles pooled for all animals & No \\
\hline Wilson and Wilson 1988 & $\begin{array}{l}\text { Bank and white breasted } \\
\text { cormorant }\end{array}$ & Individual dive cycles pooled for all animals & Yes \\
\hline Wilson and Quintana 2004 & Imperial cormorant & Individual dive cycles pooled for all animals & Yes \\
\hline
\end{tabular}

*Same population as Costa and Gales (2000) but different year and mostly different individuals

previous dive's debt, and a preparatory phase that builds reserves for the subsequent dive. During the preparatory phase, the tidal volume inspired (as determined by number of breathes and beak angle of penguins), correlated with both the dive duration and depth of the succeeding dive, suggesting penguins knew in advance their targeted depth (Wilson 2003). Consistent with this notion, pinniped data derived from 3-dimensional dive profiles (Simpkins et al. 2001) and animalborne cameras (Watanabe et al. 2003, Mori et al. 2005) suggests that almost all foraging occurs at the bottom of dives, rather than during descent and ascent. Foraging during descent or ascent might occur during exploratory dives, but these do not represent behaviour when resources have been found and are being exploited through a series of dives (Mori et al. 2002).

The above points are of practical importance. As argued below, the time spent foraging at a resource patch might reveal risk-energy tradeoffs faced by diving animals. To date, however, most diving studies are based on time-at-depth data and lack the animalborne cameras (Watanabe et al. 2003) required to actually record whether a forager is in a resource patch. Until use of this technology becomes more widespread, we assume, as suggested by others (Simpkins et al. 2001, Mori et al. 2002, 2005, Watanabe et al. 2003), that the time spent at the bottom of a dive (i.e. within $80-90 \%$ of maximum depth) represents residence time at a resource patch.

\section{Energy maximisation}

Energy-maximising models make a broad range of predictions. Here we summarize only those that we later address from a fear-energy optimising perspective.

While longer surface intervals allow longer dives, and therefore access to deeper prey or more time to feed within a patch, feeding and breathing are mutually exclusive. Furthermore, physiological constraints make the rate of oxygen gain a decelerating function of time at the surface (Kramer 1988). Thus, energy maximising models assume that optimal surface intervals maximise either the proportion of a dive cycle spent at a prey patch, net energy gain, or efficiency. Their general prediction is for dive duration to increase with depth, and for longer dives to require longer surfacings (Kramer 1988, Houston and Carbone 1992), which 
field data generally support (Wilson and Wilson 1988, Croll et al. 1992, Chappell et al. 1993, Boyd et al. 1995, Boyd 1997; but see Beck et al. 2003).

From an energy-maximising perspective, time at the foraging patch optimises tradeoffs between oxygen constraints on dive duration, travel costs, and intake rate as a function of time at the patch. Based on travel costs and assuming net energy gain or efficiency as the relevant currencies, Houston and Carbone (1992) predicted that patch residence times increase with depth initially, until longer travel to deeper strata leaves limits the oxygen available to forage at the patch. Beyond that point, patch residence time is predicted to decline with depth (Houston and Carbone 1992), unless anaerobic metabolism is invoked (Carbone and Houston 1996, Mori 1998a). Only a small proportion of dives, however, tends to be within the depth range where predicted patch residence time decreases with depth (Croll et al. 1992, Boyd 1997, Mattlin et al. 1998).

Using prey encounter rate as the currency to maximise, Thompson and Fedak (2001) also predicted an increase in mean patch residence time with increasing depth. During deep dives, according to their model, it is optimal to always have long patch residence times, even if prey are not being encountered, because the time costs of ascent and descent reduce the benefits of givingup early (i.e. before approaching the aerobic dive limit). In contrast, during shallow dives it is optimal to end a dive early when prey are not being encountered because travel is short, but the diver should not give up early if prey are being encountered. Empirical support is mixed for the prediction that patch residence time increases with depth except when dives are very deep (Table 1).

\section{Fear-energy optimisation}

\section{Fear at the surface}

Heithaus and Frid (2003) compared optimal surface intervals over the course of a foraging bout (series of dive cycles) to a fixed depth as predicted by a fear-based rule - minimise the ratio of mortality risk $\mu$ and energy gain g (Gilliam and Fraser 1987) - and by net energy maximisation. The ' $\mu$ over g' rule had been widely applied in other contexts (Lima 1998), yet this was its first application to optimal diving theory. When instantaneous predation risk was assumed to not change or to increase with the duration of a single surface interval, the fear-based currency resulted in shorter surface intervals, and consequently shorter and more frequent dives, than those predicted by the energy maximising currency. When instantaneous predation risk was assumed to decrease with the duration of a single surfacing, the fear based currency resulted in longer surface intervals relative to those predicted by the energy maximising currency, thereby increasing dive durations and reducing the number of dangerous surfacings per foraging bout.

The assumption of increasing instantaneous risk (IIR) might apply when breathing precludes monitoring of the underwater environment and submerged predators threaten. Pinnipeds and sea turtles at risk from sharks are examples (Le Boeuf and Crocker 1996, Heithaus et al. 2005). The assumption of unchanging instantaneous risk (UIR) might apply when predators can approach either submerged or at the surface, but the diver can monitor only the surface while breathing. Examples include pinnipeds and sea birds at risk from killer whales (Williams et al. 1990, Saulitis et al. 2000). The assumption of decreasing instantaneous risk (DIR) likely applies to seabirds under risk from aerial predation (Dekker and Bogaert 1997); seabirds in this situation may be unable to determine the presence of a predator and be most vulnerable upon surfacing, but can be vigilant of the surrounding air space shortly after and dive to escape from an approaching threat. Assuming that human disturbance is analogous to predation risk (Frid and Dill 2002), diving animals exposed to motorboat traffic might also experience DIR at the surface.

Field data can test predictions from Heithaus and Frid (2003) only if diving behaviour is measured concurrently with temporal or spatial variability in predation risk and resources. We could not find such data in the published literature. The following examples, however, begin to build a case.

Our ongoing analyses of the loggerhead sea turtle (Caretta caretta) under risk from tiger sharks (Galeocerdo cuvier) in Shark Bay, Western Australia (Heithaus et al. 2005) is consistent with predictions that assume IIR or UIR. During periods of high shark abundance (Heithaus 2001), the surface intervals and dive durations of adult female and juvenile loggerhead turtles shortened when seasonal shark abundance decreased (unpubl.). Similarly, bottlenose dolphins (Tursiops truncatus) rested less at the surface and increased dive duration, at an energetic cost, when disturbed by motorboats (Lusseau 2003, 2004). The longer dives and decreased rate of surfacings is consistent with DIR predictions from Heithaus and Frid (2003). That is, dolphins may have increased dive duration to reduce the frequency of exposure to the initial period of a surface interval which, under the DIR assumption, would be associated with the greatest perceived risk.

\section{Fear at the foraging patch}

As described earlier, an energy maximising perspective predicts an increase in patch residence time with depth, except when aerobic dives are very deep (Houston and Carbone 1992, Mori 1998a, Thompson and Fedak 
2001). In contrast, a predation risk framework predicts that time allocation among different habitats should minimise the ratio of mortality risk to net energy intake (Gilliam and Fraser 1987). Individuals should depart dangerous patches earlier and compromise their energy gain according to the level of perceived risk (Lima and Dill 1990, Lima 1998, Brown and Kotler 2004).

Extending this framework to danger at the underwater foraging patch is simple: For a given depth and resource quality, patch residence under predation risk should be shorter than that maximising the proportion of the dive cycle spent at that patch, with the rest of the dive cycle adjusting accordingly. General responses might be predicted by applying a predation risk discount to functional shapes derived from EM models (Kramer 1988, Houston and Carbone 1992). We illustrate this approach with a simple model inspired by harbour seals in Prince William Sound (Frid et al., in press), whose probability of encountering a Pacific sleeper shark may be very low in the upper $50 \mathrm{~m}$ of the water column, but rises as depth increases (Frid 2006, Table V in Hulbert et al. 2006). Thus, instantaneous predation risk at the foraging patch is assumed to increase with depth, which might be the general case when deep-water sharks (Cherel and Duhamel 2004, Skomal and Benz 2004) are potential predators. The model derived below is not relevant when predation risk is greatest at the surface, as appears to be case when white sharks or tiger sharks are the main predator (Le Boeuf and Crocker 1996, Heithaus et al. 2005).

Assume that descent and ascent rates accelerate with depth (Kooyman and Kooyman 1995, Crocker et al. 2001), and therefore total travel time between the surface and the foraging patch $t$ increases with depth $d$ at a decelerating rate, $\mathrm{t}=\mathrm{kd}^{\mathrm{q}}$, where $0<\mathrm{q}<1$ and $\mathrm{k}$ is a constant with no bearing on the functional shape (as is the case for other constants presented below). Similarly, patch residence time $b$ is described as $b=c t^{\theta}$, where $c$ is a constant and $0>\theta<1$ (we exclude the deeper range of dives where the function inverts: Houston and Carbone 1992), and time uploading oxygen at the surface prior to a dive, $s$, is described as $s=\mathrm{D}^{\mathrm{y}}$, where $\mathrm{D}$ is total dive duration, or $\mathrm{t}+\mathrm{b}$, and $0>\gamma<1$ (Kramer 1988).

Next assume that perceived safety at the foraging patch, $\omega$, decreases with depth at a decelerating rate $\omega=\mathrm{md}^{\mu}$, where $\mathrm{m}$ is a constant, $\mu$ a predation risk exponent with values $\geq 0$ and $<1$, and $\omega_{\max }=1$. Fear discounts patch residence time such that $\mathrm{b}$ becomes $b_{\text {fear }}=\omega$ b. It follows that if $\omega=1$ (i.e. $m=1$ and $\mu=$ $0)$ there is no predation risk influence on patch residence time, but decreasing values of $\omega$ (i.e. increasing values of $\mu$ ) predict earlier patch departures. Replacing $b$ with $b_{\text {fear }}$ in the earlier expressions recalculates other components of the dive cycle. Figure 1 represents examples of predicted patch residence as a
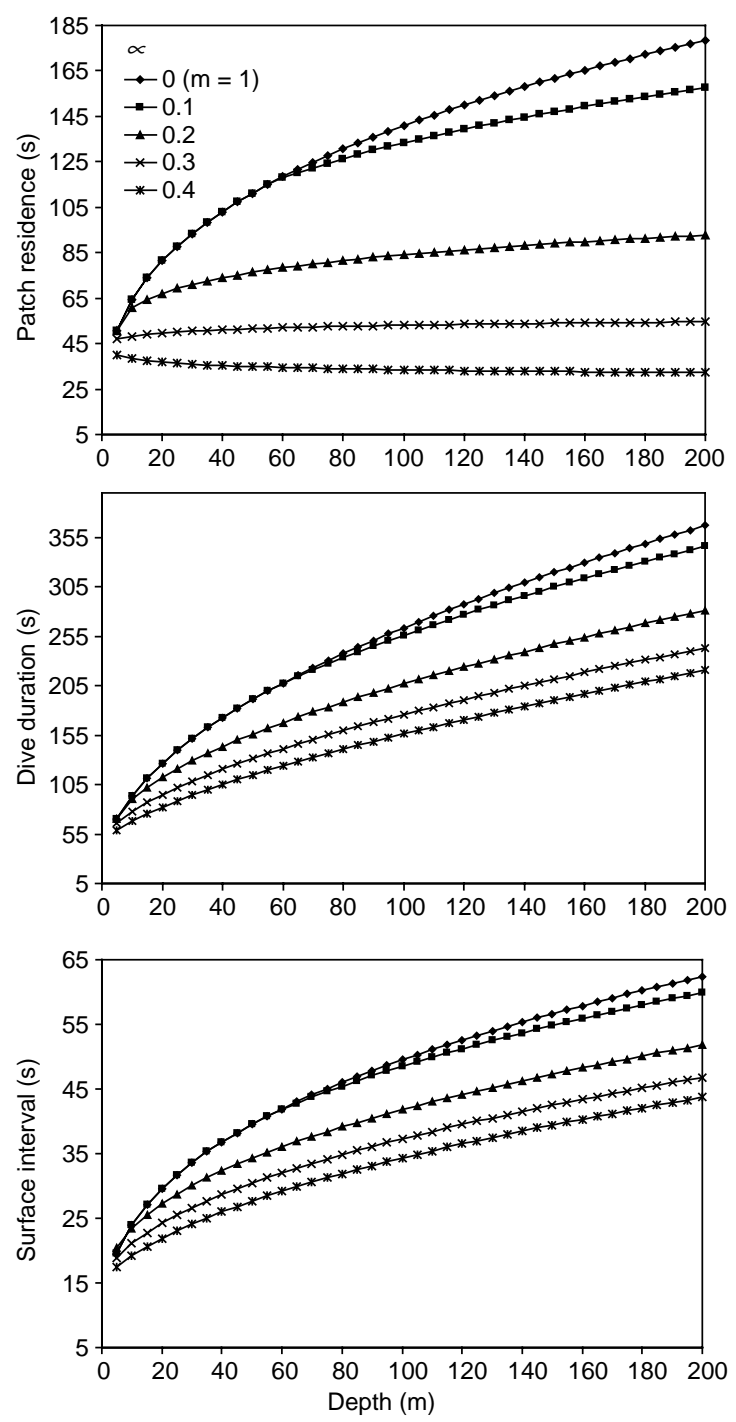

Fig. 1. Example of predicted durations of patch residence time, total dive duration and surface intervals in relation to depth for various predation risk scenarios (i.e. values of $\mu$ ). Parameterization was as follows: $\mathrm{k}=7.06, \mathrm{q}=0.62, \mathrm{c}=10$, $\theta=0.55, \gamma=0.7$, and $m=1.5$ (except for the fear-free scenario, where $\mathrm{m}=1$ ). To maintain the condition that $\omega_{\max }=1$, a chop function was applied for $\mu=0.1$ and depth $\leq 60$. See text for details.

function of depth for a fear-free scenario vs various values of $\mu$.

\section{Some case studies}

Empirical studies of pinnipeds and seabirds often do not support the prediction from EM currencies that patch residence time increases with depth, unless aerobic dives are very deep (Table 1). Here we consider 
the theoretical plausibility that predation risk influenced time at the foraging patch in cases that were inconsistent with the EM framework.

Data on Adélie penguins (Pygoscelis adeliae) shows an increase in dive duration with depth, while patch residence time decreases slightly with depth (Fig. $7 \mathrm{a}-\mathrm{b}$ of Chappell et al. 1993). Our model suggests that perceived risk for penguins increases with depth at a fast rate (see predictions for $\mu=0.4$ in Fig. 1a). While predation on penguins has been reported only at the surface (Todd 1988), an influence of risk from submerged predators on the penguins' dive cycle organisation seems theoretically plausible.

Similarly, several pinniped data sets reporting diving variables as individual means are qualitatively consistent with predictions from Fig. 1 Fear may have influenced the patch residence times of grey seals (Halichoerus grypus) in Atlantic Canada, Australian sea lions (Neophoca cinerea), New Zealand sea lions (Phocarctos hookeri), and harbour seals (Phoca vitulina) in Prince William Sound Alaska, given the shallow positive slopes, lack of relationship, or negative slopes between patch residence time and depth (Fig. 2). New Zealand fur seals (Arctocephalus forsteri), however, are one exception (see Table 1 for others), as the steep positive slope between patch residence time and diving depth suggests no substantial predation risk at the foraging patch (Fig. 2).

Our data on an Alaskan population of harbour seals (reanalysed from Frid et al., in press), which yield negative slopes in Fig. 2, provide some ground-truthing for the assumption that observed deviations from EM predictions signal fear at the foraging patch. Time-atdepth data and acoustic surveys of fish suggest nonlinear positive relationships between diving depth and a seal's probability of encountering resources and a potential predator, the Pacific sleeper shark (Frid et al., in press, Hulbert et al. 2006). During the late winter season considered by Frid (2006), the probability that a seal will encounter a shark appears to be very low in the upper $50 \mathrm{~m}$ of the water column, rises steeply with increasing depth to about $150 \mathrm{~m}$, and then decreases with further depth. (Although the depth distribution of these probabilities would shift seasonally, the upper 50 $\mathrm{m}$ stratum would always be safest; Hulbert et al. 2006). From a FEO perspective, we expect plots that include each dive cycle, rather than mean dive parameters of individuals (Fig. 2), to show a strong positive relationship between patch residence time and depth in the upper $50 \mathrm{~m}$ strata, but that relationship should be very weak or absent for dives in the range of 50 to $150 \mathrm{~m}$. Although some individual variation is present (likely reflecting individual differences in risk-taking), plots of the data (Frid et al., in press) are generally consistent with this prediction.

While little is known about predation risk for other pinnipeds in Fig. 2, sharks likely are the sources of perceived risk at the foraging patch for New Zealand sea lions (Gales 2002) and grey seals (Brodie and Beck 1983, Lucas and Stobo 2000). Differences in

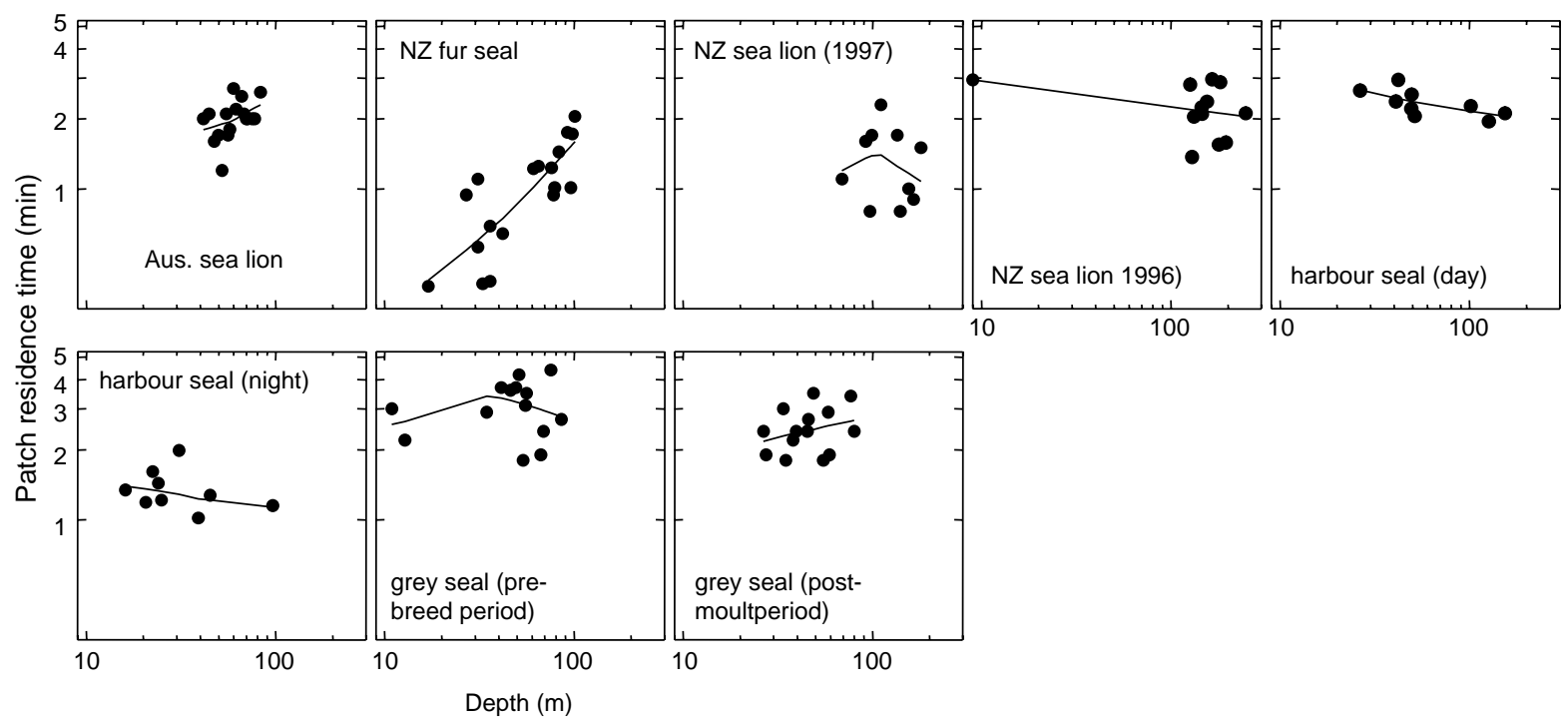

Fig. 2. Empirical data on individual means for patch residence time in relation to depth for Australian sea lions (Table 4 in Costa and Gales 2003), New Zealand fur seals (Table 2 in Mattlin et al. 1998), New Zealand sea lions during 1997 (Table 2 in Costa and Gales 2000) and 1996 (Table 3 in Crocker et al. 2001), harbour seals (reanalysed from Frid et al., in press) and grey seals (Table 2 in Beck et al. 2000). Axes are log10-transformed, and regression lines are a drawn with a LOWESS smoother with tension $=1$ (Wilkinson 2004). Except for our harbour seal work, this figure is limited to published studies with tables from which we could extract these data. 
y-intercepts between studies shown in Fig. 2 are notable and possibly reflect differences in body size (which affects predator vulnerability and maximum diving capacity) or different resource and predator distributions. For harbour seals, the lower intercept during the night likely reflects a nocturnal increase at shallow strata in both sleeper sharks risk and fish biomass (Frid et al., in press, Hulbert et al. 2006).

The case of grey seals in Atlantic Canada is intriguing. Their diving behaviour varies according to gender (Beck et al. 2003). Males are approximately 1.5 times larger (by weight) and dive deeper than females, yet mean dive durations, patch residence times and surface intervals are shorter for males than for females (Fig. 3a). Although the average depth difference between the sexes is small, $57 \mathrm{~m}$ for males vs $49 \mathrm{~m}$ for females, it contradicts the energy maximising predictions that patch residence time should increase
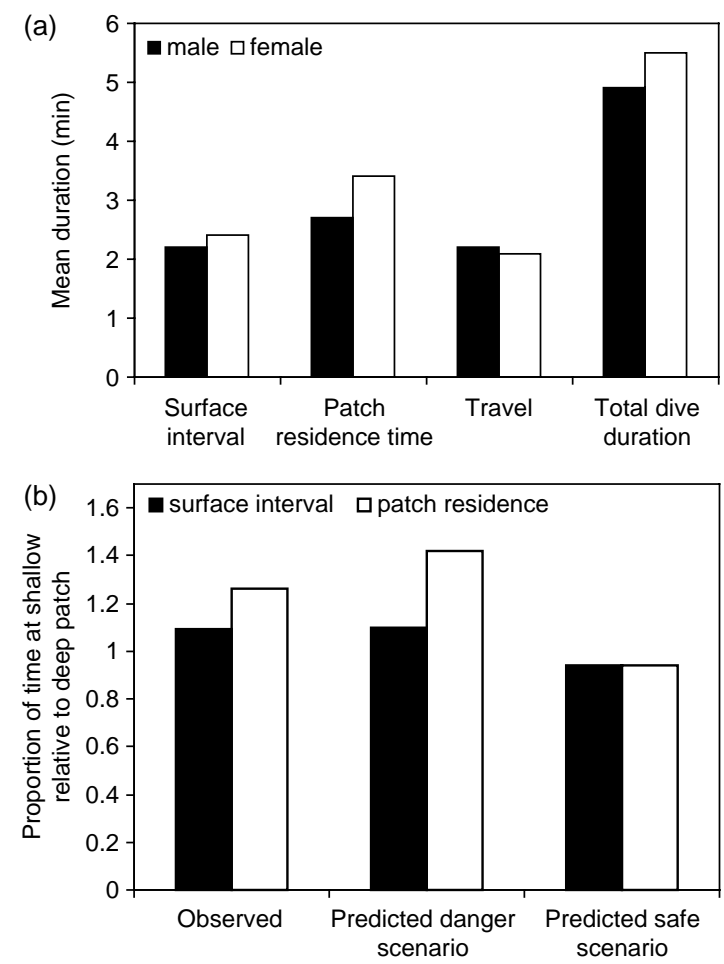

Fig. 3. (A) Average dive parameters for adult male and female grey seals at Sable Island (Table 2 in Beck et al. 2003). (B) Proportions of time spent in dive cycle components when diving to the shallow patch (49 m for "observed", $50 \mathrm{~m}$ for "predicted") relative to when diving to the deep patch $(57 \mathrm{~m}$ for "observed", $60 \mathrm{~m}$ for "predicted") for observed data and predicted scenarios. The "observed" data are the ratio of female to male durations in panel (A). The "predicted danger scenario" is calculated from Fig. 1 as the ratio of the fear-free prediction at $50 \mathrm{~m}$ to the $\mu=0.3$ prediction for $60 \mathrm{~m}$. Similarly, the "predicted safe scenario" is the ratio of fear-free predictions for 50 and $60 \mathrm{~m}$ in Fig. 1. with depth. Also, data contradict the prediction that, due to the allometry of diving capacity, larger animals should dive longer than smaller animals (Mori 1998b). In fact, Beck et al. (2003: 785) emphasise that the direction of the observed differences was contrary to that predicted based on the energy requirements of the larger sex'. Possible explanations suggested by Beck et al. (2003) are that males a) are more efficient foragers and require less time at the patch than females for a similar net gain, and b) can afford a wider range of prey types than females because their larger size enhances digestion of low quality foods. Not exclusive with these explanations, our fear-based prediction (Fig. 1) may be relevant. In a fear-free scenario, surface and patch residence times for $50 \mathrm{~m}$ dives should be shorter than for $60 \mathrm{~m}$ dives (the approximate mean diving depth of female and male grey seals, respectively) by a proportionately similar decrement. In the grey seal data, however, both surface and patch residence times are greater for the shallower dives, and the increment is proportionately greater for patch residence time (Fig. 3b). Our model predicts a similar pattern if we assume that fear does not discount patch residence time at $50 \mathrm{~m}$, but does have an effect at $60 \mathrm{~m}$ (Fig. 3b). Therefore, it is theoretically plausible that risk from one or more local shark species (Brodie and Beck 1983, Lucas and Stobo 2000) influenced the seal's diving behaviour.

A devil's advocate might argue that the FEO prediction over-interprets the data because the average depth difference between the genders was only $8 \mathrm{~m}$. While a larger difference would be more convincing, the slightly deeper strata used by males could be a boundary for a shared resource that mediates shark predation on seals (Dill et al. 2003). If available, data on diet overlap between the relevant shark species and grey seals, in conjunction with time-at-depth data for the sharks and acoustic data on the depth distribution of shared resources could test this hypothesis.

\section{Conclusion and brief prospectus}

Most research on diving behaviour ignores the wellestablished tenet that predation risk affects optimal decision making. Based on our literature examples and a simple model, we suggest that fear from submerged predators in some systems might be influencing patch residence time, and therefore the duration of other dive cycle components. One of our earlier models, however, predicts that predation risk at the surface may indirectly affect patch residence time by affecting the oxygen load, and consequently the dive duration available to exploit resources at a given depth (Heithaus and Frid 2003). If both models make the same prediction yet invoke different mechanisms, how might we tell 
whether observed deviations from EM predictions signal fear at the surface, the foraging patch, or a synergy of both? The answer is, at least partly, in the natural history of potential predators. If predators known to hunt at the surface, (e.g. killer whales, great white sharks) are unlikely to be present, then fear at the foraging patch becomes suspect. Of course, a diving species may be exposed to surface and deep water predators simultaneously, which calls for more challenging but still feasible theoretical detective work (Frid et al., in press). Our main point is that it is quite plausible for fear to alter dive cycle organisation and compromise energy gain, and observed deviations from EM predictions might signal possible cases.

The model presented here assumes that a positive relationship between instantaneous predation risk at the foraging patch and depth is driven by expected predator encounter rates. Other factors, however, might produce a similar effect. Deeper dives correlate with longer travel from the surface, and foragers at a deep patch have lower oxygen stores available for escape from a predator. Further, decreased light levels in deeper strata may hinder the early detection of a predator, particularly for species lacking alternative non-visual sensors (Dehnhardt et al. 2001). Consequently, increased oxygen consumption and lower light levels, independently or combined, might increase instantaneous predation risk at deeper resource patches, leading to shorter patch residence times than those predicted by EM models. These dynamics should apply even when expected predator encounter rates do not covary with depth, thereby providing alternative, but not mutually exclusive, mechanisms for the predictions illustrated in Fig. 1.

While our framework might explain some discrepancies between empirical data and predictions from EM currencies, we do not expect fear to always be relevant. For instance, Wilson and Wilson (1988) studied four cormorant species in the same bay. The behaviour of two of the species fits our FEO predictions, while the behaviour of the other two is consistent with EM predictions (Table 1). Perhaps interspecific differences in resource use are operative in this case (Wilson and Wilson 1988).

This paper should be viewed merely as a catalyst for the many tasks that lay ahead. To begin, empirical data on danger from submerged predators are needed to interpret the variable support for energy-maximising predictions on patch residence time in relation to depth (Table 1). A good start would be an analysis relating area- and depth-specific distributions of different shark species, which might be derived from fishery data, to the diving behaviour of different pinniped populations. Inferences would be strengthened by field studies in which the behaviour of predator and prey are studied concurrently with the distribution of the prey's resource
(Frid et al., in press), and by laboratory studies manipulating risk of predation in different parts of the water column for model organisms (e.g. freshwater turtles).

Existing theory, of course, requires expansion. Our simple model implicitly assumed a linear energy intake function for patch residence time, while changes to the functional shape of this relationship would affect the predicted organisation of the dive cycle that would optimise safety and energy gain (Heithaus and Frid 2003). Further, diving is a dynamic process, and dynamic state variable models allow predicted optimal decisions to adjust to states with short-term consequences, such as oxygen level, and more long-term effects on residual reproductive value, such as energy stores (Ydenberg and Clark 1989, Clark and Mangel 2000, Frid et al. 2006). This modeling technique could, for instance, provide insight into how patch residence time (and correlated dive cycle components) respond to the influence of depth-specific light levels and oxygen stores on predator detection and escape.

The predation risk framework should apply to other aspects of diving behaviour. For instance, descent and ascent rates are predicted to optimise costs of transport (Thompson et al. 1993), but a FEO framework might predict that it is optimal to exceed the travel rates that maximise net energy gain to optimise time spent travelling through dangerous strata. Similarly, the extended surface intervals that follow long anaerobic dives may maximise net energy gain if they allow exploitation of ephemeral resource aggregations (Ydenberg and Clark 1989), yet a FEO framework might use danger at the surface to discount the expected payoff of those anaerobic dives.

Fear-energy optimising hypotheses about individual behaviour have enhanced understanding of population and community dynamics in other systems (Schmitz et al. 2004). Much has been learned by elucidating survival and reproduction as the outcome of synergistic effects of resources and predators, rather than as top down vs. bottom up dichotomies (McNamara and Houston 1987, Sinclair and Arcese 1995). That framework, combined with theory presented here, can suggest hypotheses on factors contributing to population declines of diving species. For instance, adjustments to the dive cycle that reduce predation risk might be unaffordable if resources are scarce. Thus, if animals are to avoid imminent starvation or substantial loss of reproductive potential, resource declines might indirectly increase predation rates by limiting the extent to which dive cycles can deviate from those that would maximize energy gain (Frid et al. 2006). The framework is also useful for predicting the indirect effects of fishery removal of large sharks, which could lead to 'fear-released' systems. One consequence might be longer patch residence times at depths that were 
previously under-utilised due to predator intimidation. Through this mechanism, a shark fishery might indirectly increase the mortality rate inflicted by diving animals on resource species that were formerly 'shielded' by top predator intimidation (Frid 2006, Frid et al., in press).

We hope that these ideas stimulate other researchers to develop new theory and test predictions on how predation risk might influence diving behaviour and its ecological consequences. In more cases than not, predators are real, even if the proverbial ostrich fails to see them.

Acknowledgements - Financial support for AF was provided by the North Pacific Research Board, the Alaska Dept of Fish and Game, the Prince William Sound Science, the Project Aware Foundation, and graduate scholarships from NSERC Canada and Simon Fraser Univ. LMD is supported by NSERC Canada (Grant A6869). HRH's research is supported by NSF grant OCE-0526065.

\section{References}

Beck, C. A. et al. 2000. Seasonal changes in buoyancy and diving behaviour of adult grey seals. - J. Exp. Biol. 203: 2323-2330.

Beck, C. A. et al. 2003. Sex differences in the diving behaviour of a size-dimorphic capital breeder: the grey seal. - Anim. Behav. 66: 777-789.

Boyd, I. L. 1997. The behavioural and physiological ecology of diving. - Trends Ecol. Evol. 12: 213-217.

Boyd, I. L. et al. 1995. Swimming speed and allocation of time during the dive cycle in Antarctic fur seals. - Anim. Behav. 50: 769-784.

Brodie, P. and Beck, B. 1983. Predation by sharks on the grey seal (Halichoerus grypus) in eastern Canada. - Can. J. Fish. Aquat. Sci. 40: 267-271.

Brown, J. S. and Kotler, B. P. 2004. Hazardous duty pay and the foraging cost of predation. - Ecol. Lett. 7: 999-1014.

Brown, J. S. et al. 1999. The ecology of fear: optimal foraging, game theory, and trophic interactions. - J. Mammal. 80: 385-399.

Carbone, C. and Houston, A. I. 1996. The optimal allocation of time over the dive cycle: an approach based on aerobic and anaerobic respiration. - Anim. Behav. 51: 12471255.

Chappell, M. A. et al. 1993. Diving behavior during foraging in breeding Adélie penguins. - Ecology 74: 1204-1215.

Cherel, Y. and Duhamel, G. 2004. Antarctic jaws: cephalopod prey of sharks in Kerguelen waters. - Deep-Sea Res. I 51: $17-31$.

Clark, C. W. and Mangel, M. 2000. Dynamic state variable models in ecology. - Oxford Univ. Press.

Costa, D. P. and Gales, N. J. 2000. Foraging energetics and diving behavior of lactating New Zealand sea lions, Phococarctos hookeri. - J. Exp. Biol. 203: 3655-3665.
Costa, D. P. and Gales, N. 2003. Energetics of a benthic diver: seasonal foraging ecology of the Australian sea lion, Neophoca cinerea. - Ecol. Monogr. 73: 27-43.

Crocker, D. E. et al. 1997. Drift diving in female northern elephant seals: implications for food processing. - Can. J. Zool. 75: 27-39.

Crocker, D. E. et al. 2001. Swimming speed and foraging strategies of New Zealand sea lions (Phocarctos hookeri). - J. Zool. (Lond.) 254: 267-277.

Croll, D. A. et al. 1992. Foraging behavioir and physiological adaptation for diving in thick-billed murres. - Ecology 73: 344-356.

Dehnhardt, G. et al. 2001. Hydrodynamic trail-following in harbor seals (Phoca vitulina). - Science 293: 102-104.

Dekker, D. and Bogaert, L. 1997. Over-ocean hunting by peregrine falcons in British Columbia. - J. Raptor Res. 41: $381-383$.

Dill, L. M. et al. 2003. Behaviorally-mediated indirect interactions in marine communities and their conservation implications. - Ecology 84: 1151-1157.

Frid, A. 2006. Optimal risk-taking theory applied to marine conservation: harbour seals in Prince William Sound. - PhD thesis, Simon Fraser Univ. Burnaby, BC, Canada.

Frid, A. and Dill, L. M. 2002. Human-caused disturbance stimuli as a form of predation risk. - Conserv. Ecol. 6: http://www.consecol.org/Journal/vol6/iss1/art11/ print.pdf.

Frid, A. et al. 2006. Do resource declines increase predation rates on North Pacific harbor seals? A behavior-based plausibility model. - Mar. Ecol. Prog. Ser. 312: 265275.

Frid, A., Dill, L. M., Thorne, R. E., Blundell, G. M. In press. Inferring prey perception of relative danger in large-scale marine systems. - Evol. Ecol. Res.

Gales, N. J. 2002. New Zealand sea lion. - In: Perrin, W. F. et al. (eds), Encyclopedia of marine mammals. Academic Press, pp. 791-794.

Gilliam, J. F. and Fraser, D. F. 1987. Habitat selection under predation hazard: test of a model with foraging minows. - Ecology 68: 1856-1862.

Hays, G. C. et al. 2001. The diving behaviour of green turtles undertaking oceanic migration to and from Ascension Island: dive durations, dive profiles, and depth distribution. - J. Exp. Biol. 204: 4093-4098.

Heithaus, M. R. 2001. The biology of tiger sharks (Galeocerdo cuvier) in Shark Bay, Western Australia: sex ratio, size distribution, diet and seasonal catch rates. - Environ. Biol. Fish. 61: 25-36.

Heithaus, M. R. and Frid, A. 2003. Optimal diving under the risk of predation. - J. Theor. Biol. 223: 79-92.

Heithaus, M. R. et al. 2005. Biology of sea turtles under risk from tiger sharks at a foraging ground. - Mar. Ecol. Prog. Ser. 288: 285-294.

Houston, A. I. and Carbone, C. 1992. The optimal allocation of time during the dive cycle. - Behav. Ecol. 3: 255-265.

Hulbert, L. et al. 2006. Depth and movement behaviour of the Pacific sleeper shark in the northeast Pacific Ocean. - J. Fish Biol. 69: 406-425.

Kooyman, G. L. and Kooyman, T. G. 1995. Diving behavior of emperor penguins nurturing chicks at Coulman Island, Antarctica. - Condor 97: 546-549. 
Kramer, D. L. 1988. The behavioral ecology of air breathing by aquatic animals. - Can. J. Zool. 66: 89-94.

Le Boeuf, B. J. and Crocker, D. E. 1996. Diving behavior of elephant seals: implications for predator avoidance. - In: Klimley, A. et al. (eds), Great white sharks: biology of Carcharodon carcharias. Academic Press, pp. 193-205.

Lima, S. L. 1998. Stress and decision making under the risk of predation: recent developments from behavioral, reproductive, and ecological perspectives. - Adv. Study Behav. 27: $215-290$.

Lima, S. L. and Dill, L. M. 1990. Behavioural decisions made under the risk of predation. - Can. J. Zool. 68: 619-640.

Lucas, Z. and Stobo, W. T. 2000. Shark-inflicted mortality on a population of harbour seals (Phoca vitulina) at Sable Island, Nova Scotia. - J. Zool. (Lond.) 252: 405-414.

Lusseau, D. 2003. Male and female bottlenose dolphins (Tursiops spp.) have different strategies to avoid interactions with tour boats in Doubtful Sound, New Zealand. - Mar. Ecol. Prog. Ser. 257: 267-274.

Lusseau, D. 2004. The hidden cost of tourism: effects of interactions with tour boats on the behavioural budget of two populations of bottlenose dolphins in Fiordland, New Zealand. - Ecol. Soc. 9: 2 \{formerly Conserv. Ecol.\} http://www.ecologyandsociety.org/vol9/iss 1/art2/.

Mattlin, R. H. et al. 1998. Seasonal dive behaviour of lactating New Zealand fur seals (Arctocephaus forsteri). - Can. J. Zool. 76: 350-360.

McNamara, J. M. and Houston, A. I. 1987. Starvation and predation as factors limiting population size. - Ecology 68: $1515-1519$.

Mori, Y. 1998a. Optimal choice of foraging depths in divers. - J. Zool. (Lond.) 245: 279-283.

Mori, Y. 1998b. The optimal patch use in divers: optimal time budget and the number of dive cycles during bout. - J. Theor. Biol. 190: 187-199.

Mori, Y. and Boyd, I. L. 2004. The behavioral basis for nonlinear functional responses and optimal foraging in Antarctic fur seals. - Ecology 85: 398-410.

Mori, Y. et al. 2002. An application of optimal diving models to diving behaviour of Brünnich's guillemots. - Anim. Behav. 64: 739-745.

Mori, Y. et al. 2005. A comparison of prey richness estimates for Weddell seals using diving profiles and image data. - Mar. Ecol. Prog. Ser. 295: 257-263.

Rubinoff, I. et al. 1986. Diving of the sea snake Pelamis platurus in the Gulf of Panama 1. Dive depth and duration. - Mar. Biol. 91: 181-191.
Saulitis, E. et al. 2000. Foraging strategies of sympatric killer whale (Orcinus orca) populations in Prince William Sound, Alaska. - Mar. Mamm. Sci. 16: 94-109.

Schmitz, O. J. et al. 2004. Trophic cascades: the primacy of trait-mediated indirect interactions. - Ecol. Lett. 7: 153163.

Simpkins, M. A. et al. 2001. Three-dimensional analysis of search behaviour by ringed seals. - Anim. Behav. 62: 6772.

Sinclair, A. R. E. and Arcese, P. 1995. Population consequences of predation-sensitive foraging: the Serengeti wildebeest. - Ecology 76: 882-891.

Skomal, G. B. and Benz, G. W. 2004. Ultrasonic tracking of Greenland sharks, Somniosus microcephalus, under Arctic ice. - Mar. Biol. 145: 489-498.

Thompson, D. and Fedak, M. A. 2001. How long should a dive last? A simple model of foraging decisions by breathhold divers in a patchy environment. - Anim. Behav. 61: 287-296.

Thompson, D. et al. 1993. How fast should I swim? Behavioural implication s of diving physiology. - Symp. Zool. Soc. Lond. 66: 349-368.

Todd, F. S. 1988. Weddel seal preys on chinstrap penguin. - Condor 90: 249-250.

Watanabe, Y. et al. 2003. Dive depths of Weddell seals in relation to vertical prey distribution as estimated by image data. - Mar. Ecol. Prog. Ser. 252: 283-288.

Wilkinson, L. 2004. Smoothing. - In: SYSTAT Software Inc. (ed.), SYSTAT 11 Statistics. SYSTAT Sotware Inc., pp. $391-422$.

Williams, A. J. et al. 1990. Killer whale Orcinus orca and seabirds: "play", predation, and association. - Mar. Ornithol. 18: 37-41.

Wilson, R. P. 2003. Penguins predict their performance. - Mar. Ecol. Prog. Ser. 249: 305-310.

Wilson, R. P. and Wilson, M.-P. T. 1988. Foraging behaviour in four sympatric cormorants. - J. Anim. Ecol. 57: 943-955.

Wilson, R. P. and Quintana, F. 2004. Surface pauses in relation to dive duration in imperial cormorants; how much time for a breather? - J. Exp. Biol. 207: 17891796.

Ydenberg, R. C. and Clark, C. W. 1989. Aerobiosis and anaerobiosis during diving by western grebes: an optimal foraging approach. - J. Theor. Biol. 139: 437-439. 